\title{
The relationship between subjectivity in managerial performance evaluation and the three dimensions of justice perception
}

\author{
Thuy-Van $\operatorname{Tran}^{1} \mathbb{D} \cdot$ Sinikka Lepistö ${ }^{2} \cdot$ Janne Järvinen ${ }^{1}$
}

Accepted: 7 April 2021 / Published online: 16 May 2021

(C) The Author(s) 2021

\begin{abstract}
This paper examines the relationship between subjectivity in performance evaluation and the three dimensions of justice perceptions in an emerging economy; prior research on this topic has primarily focused solely on the advanced capitalist economies of Western nations. The paper also aims to expand on existing research by focusing on the role of interactional justice perceptions in relation to subjective evaluation (Byrne et al. in Hum Resour Manag J 22(2):129-147; Folger and Cropanzano, in Organizational justice and human resource management, Sage, Thousand Oaks, 1998). Results from a survey of 160 middle managers in Vietnam indicate that subjective evaluation is associated predominantly with negative effects. We found that, in an emerging economy like that of Vietnam, subjective evaluation reduces interactional justice perception, which in turn decreases the perception of procedural and distributive justice. The mediating effects suggest that the reason subjective evaluation influences employee procedural/distributive justice perceptions lies in the interactional justice perceived from supervisors. This research clarifies the effects of subjective evaluation on the dimensions of justice perception and contributes to the literature on performance evaluation and organizational justice in a non-Western context. It also highlights the importance of respect and communication for fairness perception in both theory and practice.
\end{abstract}

Keywords Subjectivity in performance evaluation - Organizational justice · Procedural justice $\cdot$ Distributive justice $\cdot$ Interactional justice $\cdot$ Emerging economies

Thuy-Van Tran

van.tran@oulu.fi

Sinikka Lepistö

sinikka.lepisto@utu.fi

Janne Järvinen

janne.t.jarvinen@oulu.fi

1 University of Oulu, P.O Box 4600, 90014 Oulu, Finland

2 Turku School of Economics, Pori Unit, University of Turku, P.O Box 170, 28101 Pori, Finland 


\section{Introduction}

Fairness or justice perception is not only a pillar of a healthy organizational culture but also essential for employee well-being (Ashkanasy, 2011). As such, it is one of the prevailing moral standards (Whiteside \& Barclay, 2016) and core elements of ethical leadership (Brown et al., 2005; Xu et al., 2016). Prior literature states that a control perceived as fair or enabling can positively affect individual behaviours and organizational outcomes (Mahama \& Cheng, 2013). Specifically, positive justice perception can promote organizational commitment (Lau \& Moser, 2008) and job satisfaction (Viswesvaran \& Ones, 2002), and enhance performance (Zainuddin \& Isa, 2019). However, low levels of justice perception, are associated with negative outcomes such as stress, retaliatory intentions or disruptive behaviour (Lau \& Oger, 2012; Silva \& Caetano, 2014; Virtanen \& Elovainio, 2018). Justice in organizational settings typically includes three forms: distributive justice, the fairness of employee outcomes; procedural justice, the fairness of procedures used to make the outcome decisions and interactional justice, the fairness of interpersonal treatment (Choon \& Embi, 2012; Colquitt et al., 2001).

Subjective judgement, which is a component of performance evaluation practices, is one of the most crucial sources of organizational justice perceptions (Folger \& Konovsky, 1989); at the same time, it can entail ethical issues. On the one hand, supervisors have an ethical and legal obligation to give accurate assessments of their subordinates' performance (Sherman \& Bohlander, 1988). On the other hand, external factors can arise and render performance evaluation a not entirely rational process (Gomez-Mejia et al., 2007). For example, supervisors' assessments can be lenient or untruthful in order to avoid conflicts, limit complaints, or win the favour of some employees (Bol, 2011). Subjective evaluation brings with it the dilemma that the judgement of superiors is not always aligned with subordinates' performance and contributions, which consequently affects the subordinates' perceived justice. Given the important role of justice perceptions in determining employee behaviour and organizational performance, the management accounting literature has dedicated increased attention to the effectiveness of subjectivity in performance evaluation and its relation to employee perceived justice (e.g. Bellavance et al., 2013; Hartmann et al., 2010; Voußem et al., 2016).

Despite the growing empirical research on subjectivity in performance evaluation and justice perceptions, we know little about the issue in non-Western settings. Researchers have revealed that the effectiveness of performance evaluation practices may differ across cultures (Brockner et al., 2001; Chang \& Hahn, 2006; Lam et al., 2002; Stammerjohan et al., 2015; Wu \& Chaturvedi, 2009). There could also be profound differences in how people of different national origins react to or perceive the justice of the same sets of controls (Chow et al., 2001; Kim \& Leung, 2007), even if justice is considered universally important (Greenberg, 2001). Hence, this study aims to fill this research gap by examining performance evaluation systems and justice perceptions in a non-Western emerging context. Vietnam was chosen as our setting because it has typical cultural characteristics of many other emerging economies, such as a high level of power 
distance and collectivism (Hofstede et al., 2010; Power et al., 2010; Walumbwa \& Lawler, 2003). The results of the study, therefore, can be applied to understanding the phenomena of management practices and justice perceptions in many other emerging markets, especially in Asia.

In the study, we examine the relationship between subjectivity in performance evaluation and justice perceptions in the Vietnamese context, as an example of emerging economies. We also aim to extend previous work by developing a model in which interactional justice is a mediator between subjective evaluation and the other two justice dimensions.

We expect that employees tend to attribute any (in)justice related to subjective evaluation primarily to their supervisors, who are directly responsible for assessing them. Interactional justice (rather than procedural or distributive justice) is the most relevant to subjective evaluation because interactional justice concerns how individuals treat and communicate with one another in the workplace (Bies \& Moag, 1986). Our model is consistent with Colquitt's suggestions (2001) that interactional justice is more related to a supervisor's evaluation than procedural and distributive justice perceptions. It also adopts the arguments from Cohen-Charash and Spector (2001) that interactional justice is an antecedent to distributive and procedural justice. The model is tested from the perspective of middle managers in their roles as subordinates, as it is important and challenging to ensure a high-quality managerial team (Sokol \& Oresick, 1986).

Our empirical analysis shows that the negative effects of subjective evaluation on employees' perceived justice are generally stronger than the positive ones, which is consistent with our predictions. Perception of interactional justice is found to be an antecedent of the other forms of justice perceptions: distributive justice and procedural justice. It significantly mediates the relationship between subjective evaluation and perceived procedural/distributive justice.

Our research provides the following contributions to the management accounting literature. First, it contributes to the growing literature on the effects of subjective evaluation on employees' justice perceptions (e.g. Bol, 2011; Hartmann et al., 2010). To the best of our knowledge, our research is the first broad assessment of the effects of subjective evaluation on all three aspects of justice perceptions. While prior literature has mainly examined the effects of subjective evaluation on perceived justice related to evaluation procedures and outcomes, we take a different perspective and focus on the effects on justice perceptions regarding supervisor treatment.

Furthermore, previous research suggests that interactional justice is an important form of justice because it is strongly associated with supervisor-related outcomes such as leader-member exchange, motivation, and commitment (Gupta \& Kumar, 2013; Masterson et al., 2000). Libby (1999) emphasizes that communication and explanations, as components of interactional justice perceptions, have a significant effect on employee performance. Nevertheless, there is still limited research on this form of justice. Our paper answers the call for more research into interactional justice perceptions (see Cohen-Charash \& Spector, 2001; Colquitt et al., 2001). We highlight the importance of interactional justice perceptions that connect subjective performance evaluation with the perceived justice of procedures and outcome 
distribution. Our results also indicate the importance of studying organizational justice concepts as three distinct but related dimensions.

Finally, the study provides insights into the phenomena of performance evaluation practices and justice perceptions in a different economy to those typically described as 'advanced capitalist economies'. It contributes to the generalizability of organizational justice theories (Greenberg \& Colquitt, 2013). This meets calls for more research into accounting in emerging economies and the convergence of accounting practices worldwide (e.g. Ezzamel \& Xiao, 2011).

Given the role of interactional justice perceptions, these findings have practical implications for applying discretion so that evaluated employees are treated with respect and are communicated with effectively, in the pursuit of positive perceived fairness and other desired outcomes. In other words, subjectivity in performance evaluation should be considered part of organizational social controls, to show consideration and concerns towards employees. For instance, a formal system could be implemented to provide and monitor feedback (such as formal appraisals, performance reviews, routine and periodic formal reporting) on a detailed and frequent basis (Libby, 1999; Pitkänen \& Lukka, 2011). Employees should also receive explanations about their performance ratings and outcomes (both rewards and punishments). Furthermore, it is vital to have management teams that can communicate competently and provide feedback effectively (Pitkänen \& Lukka, 2011).

The remainder of the paper is structured as follows. Section 2 presents our study's theoretical background and Sect. 3 develops our hypotheses about the relationship between subjectivity in performance evaluation and the three dimensions of justice perception. In Sect. 4, we describe the design of the empirical study and present our results in Sect. 5. Finally, we discuss the findings and their implications in Sect. 6.

\section{Literature review}

\subsection{Subjectivity in performance evaluation}

According to Baker et al. (1994), a good performance metric should be accurate, informative, and timely, and should not expose those evaluated to undue risk. Objective performance measures linked to quantitative and verifiable targets can hardly meet all the criteria because they can be too aggregate, narrow, and retrospective (Baker et al., 1994; Bol, 2008; Ittner et al. 2003; Prendergast \& Topel, 1993). Furthermore, objective measures are generally unavailable for certain functions (such as HR, accounting, or legal) and/or frequently changing environments (Frederiksen et al. 2017). Thus, in their role as the subject of an evaluation, middle managers might put more effort into job aspects that are more easily measured and well compensated, and avoid other tasks for which they are not rewarded (Bol, 2008; van der Kolk \& Kaufmann, 2018). In addition, managerial performance and target achievements can be affected by uncontrollable and unforeseeable events, such as economic factors or competitors' actions. Using purely objective measurements can introduce noise and reduce the effectiveness of the performance assessments (Bol, 2008). It can also reduce employees' effort if the outcomes they receive are only linked to the 
target achievements. In sum, objective measures are inadequate and insufficient for measuring middle managers' multifaceted tasks and their contribution to the value of the organization (Baker et al., 1994; Bol, 2008; Ittner et al., 2003; Prendergast \& Topel, 1993).

Subjective components have been described as a valuable complement to objective measures in a performance evaluation system (Gibbs et al., 2004; Golman \& Bhatia, 2012). Subjectivity refers to the discretion that superiors display in evaluating their subordinates' performance and determining their salaries and bonuses (Chow et al. 2006; Moers, 2005). It can be derived from their judgement of the subordinates' qualitative performance, such as knowledge-sharing and communication skills (Bellavance et al., 2013; Chow et al., 2006; Moers, 2005). Subjectivity can take the form of ex-post adjustment in the weighting of objective performance measurements. It can also relate to flexibility in adjusting evaluations and bonuses based on factors other than pre-specified criteria (Ittner et al., 2003; Woods, 2012). These forms of adjustments normally involve considering uncontrollable events and making adjustments to ex-ante targets to filter out the effects of those events and modify performance targets (Höppe \& Moers, 2011; Murphy \& Oyer, 2001). Subjectivity in performance evaluation, in any form, is heavily influenced by the personal perceptions, beliefs, and experiences of the person doing the evaluation (Choon \& Embi, 2012).

Previous studies have taken different approaches to the concept of subjectivity in performance evaluation. One research stream investigates subjectivity in determining salaries and rewards (Gibbs et al. 2004; Voußem et al., 2016), while another focuses on performance evaluation as a process distinct from bonus systems (Bol \& Smith, 2011; Van Rinsum \& Verbeeten, 2012). An additional stream of research examines supervisor discretion in evaluating performance and translating the observed performance into rewards (Bol, 2011; Höppe \& Moers, 2011). We follow this last approach because it is necessary to consider both the evaluation and reward systems to understand their impacts on all three aspects of justice perceptions. Our use of the concept refers to any subjective judgement by superiors in evaluating middle managers' performance and determining their bonuses.

Subjective evaluation is informative with regard to the qualitative aspects of employees' performance (Baiman \& Rajan, 1995; Baker et al., 1994). It can provide a broader view, beyond measuring just a few narrow aspects of performance (Lau $\&$ Sholihin, 2005). Since the subjective components are often non-financial, they can be relevant to both short- and long-term objectives. They are not only outcomebased measurements derived from past efforts, but also drive future performance (Lau \& Sholihin, 2005). Ex-post adjustments as forms of subjectivity can filter out the effects of uncontrollable events and enhance individual performance (Kelly et al., 2015). As a result, subjectivity in performance evaluation can benefit firms by reducing incentive costs and risks (Gibbs et al., 2004; Ittner et al., 2003; Prendergast \& Topel, 1993).

Nevertheless, prior research has highlighted several negative consequences of subjective performance evaluation. It can be inaccurate and biased because subjectivity is not always transparent (Marginson et al., 2014; Van Rinsum \& Verbeeten, 2012). Subjective evaluation can also cause favouritism and opportunism from both 
evaluatees and evaluators (Cheng \& Coyte, 2014; Ittner et al., 2003; Moers, 2005; Woods, 2012). This can be problematic for making decisions regarding personnel and future incentives (Krishnan et al., 2005; Moers, 2005; Otley, 1999).

\subsection{Perceptions of organizational justice}

Organizational justice relates to perceptions of fairness in a workplace, which leads individuals to conclude that they are being treated fairly or unfairly (Folger \& Cropanzano, 1998; Fortin, 2008). It is a crucial issue in both theory and practice, because of its influence on organizational outcomes and the attitudes of organization members (Cropanzano \& Greenberg, 1997; Hopwood, 1972; Lind \& Tyler, 1988). Positive perceptions of justice encourage cooperation, improve employee satisfaction and performance, and promote the acceptance of organizational change (Lau \& Oger, 2012; Zainuddin \& Isa, 2019), whereas the absence of justice can lead to negative effects on employees' well-being and various forms of disruptive behaviour (Silva \& Caetano, 2014). As with most papers in this research stream, the current paper uses the terms 'justice' and 'fairness' interchangeably.

The organizational justice theory introduced by Folger and Cropanzano (1998) generally classifies justice into three main dimensions: procedural justice, distributive justice, and interactional justice. Procedural justice is the fairness of the rules and processes employed to decide outcome allocations (Cropanzano \& Greenberg, 1997; Folger \& Konovsky, 1989). It is 'the judgement that procedures and social processes are fair' (Lind \& Tyler, 1988). Distributive justice is the fairness of those outcome allocations themselves (Cropanzano \& Greenberg, 1997; Folger \& Konovsky, 1989; Greenberg, 1987). It is usually based on the principle of equity between individual benefits and their proportional inputs (e.g. education, intelligence and experience) (Leventhal, 1980; Lindquist, 1995). The third type of justice, interactional justice, relates to the quality of communication between superiors and subordinates (Bies \& Moag, 1986). This involves the extent to which superiors treat their subordinates with respect and provide candid, sufficient explanations for their evaluation decisions (Simons \& Roberson, 2003). The three dimensions of organizational justice have positive and varying roles in employees' behaviour, satisfaction, and performance (Maaniemi \& Hakonen, 2008).

It should be noted that some previous studies consider interactional justice to be part of procedural justice, while many others maintain the distinction between these concepts (Bies, 2005; Colquitt, 2001). Interactional justice distinguishes itself from procedural justice by being about the communication provided to employees during evaluation processes and explanations, instead of about the procedures themselves. Conceptual reviews and meta-analytic evidence from Colquitt and Greenberg (2003) also separate those concepts because of their different antecedents and descendants. Interactional justice perception is more strongly associated with supervisor-related outcomes such as leader-member exchange and commitment, while procedural justice perception is more strongly related to organizational-relevant outcomes such as organizational commitment (Masterson et al., 2000). Prior studies show that those who perceive high interactional justice are more likely to show high motivation and 
put extra effort into their work (Gupta \& Kumar, 2013). In this study, we examine interactional justice as a separate form of justice to better understand different aspects of justice perceptions.

\subsection{National culture}

National culture is defined as 'the collective programming of the mind which distinguishes the members of one group or society from those of another' (Hofstede, 1980 , p. 25), and is approached in different ways by researchers. In the study, we focus on two dimensions: power distance and individualism/collectivism (Hofstede, 1980), since they are considered the most relevant to employees' reactions to various controls in organizations. They are the most common dimensions used by researchers in considering cultural impacts on management and accounting practices (Chow et al., 2001; Cohen \& Avrahami, 2006). Because of their frequent appearance in accounting research, we do not present their detailed descriptions in the current study.

Emerging markets are typically different from advanced markets in terms of cultural values. Individuals in emerging countries generally show stronger collectivism and power distance, while advanced markets are characterised by high levels of individualism and low power distance (Hofstede et al., 2010; Power et al., 2010; Walumbwa \& Lawler, 2003). Vietnam was chosen as representative of emerging economies because Vietnamese culture, characterised by high collectivism and power distance, reflects the typical cultural values and orientation of many emerging markets (Du \& Choi, 2010). In Vietnam, management and performance evaluation practices emphasise harmony in social relationships, are characterised by seniority preference and limited feedback (Hempel, 2001; Shen, 2004; Warner, 2010).

Empirical studies have found similarities and differences in the effectiveness of management practices and employee attitudes across cultures (e.g. Chang \& Hahn, 2006; Stammerjohan et al., 2015; Wu \& Chaturvedi, 2009). For instance, Chang and Hahn (2006) indicate that certain types of control practices affect employees from Korea and the US in a consistent manner, regardless of their cultural differences. On the other hand, some research indicates that some management practices may be only effective in certain national settings, but ineffective or even dysfunctional in others (Chow et al., 2001). Ng et al. (2011) examine the impacts of culture on how employees react to rating biases (rating leniency and halo), and find that employees with high power distance values are more susceptible to rating bias than those with low values.

As argued by many researchers (Folger \& Skarlicki, 2008; Greenberg, 2001), justice is universally important in interpersonal relations. This is because beyond sociocultural contexts, a positive justice perception has crucial impacts on organizational outcomes and employee behaviour (Lind \& Tyler, 1988). Lam et al. (2002), Leung et al. (2001) and Morris and Leung (2000) find that the positive effects of perceived justice on employee outcomes (performance, absenteeism, and job satisfaction) are similar in all cultural contexts. At the same time, other research shows differences across cultures in certain aspects of justice perceptions. For example, the degree to 
which justice perceptions influence individual outcomes may differ in different cultures. Erdogan and Liden (2006) find that the relation between interactional justice and leader-member exchange (LMX) is weaker for individuals high in collectivism than those low in collectivism. Research by Kim and Leung (2007) indicates that organizational injustice has a stronger negative impact on job satisfaction and intention to leave in America than in China, Korea, and Japan. They also find that distributive justice matters more in the formation of overall fairness for Chinese and Koreans than for Americans and Japanese. Interactional justice, by contrast, shapes overall fairness more strongly for Americans and Japanese than for Chinese and Koreans.

\section{Hypothesis development}

Based on the existing literature, we propose hypotheses for testing the relationships between subjectivity in performance evaluations and the three dimensions of organizational justice perception.

\subsection{Subjectivity in performance evaluation and interactional justice perceptions}

Subjective evaluation usually involves the adoption of broad and varied non-financial performance measures. It enables assessments of job aspects that are value-adding but cannot be measured in an objective manner, such as work attitudes, communication and knowledge-sharing (Voußem et al., 2016). As for middle managers as evaluatees, subjective evaluation can help to assess their performance on management tasks which relates to leading and increasing the work quality of their teams (Sherf, 2016). A supervisor who includes such aspects in his/her assessments is likely to increase subordinates' sense of interactional justice because their effort on the tasks is recognised and appreciated.

In addition, subjectivity in performance evaluation, which includes flexibility based on factors other than performance measures specified ex-ante, can enable evaluators to correct noisy objective targets and better capture employee effort. Specifically, they can neutralise the effects of unforeseeable events that are not under employees' control but influence their performance and rewards (Bol \& Smith, 2011; Kelly et al., 2015). Supervisors can show benevolence and concern for their subordinates by being considerate in giving performance ratings (Lau \& Tan, 2006). Applying subjective evaluation can also provide supervisors and subordinates with opportunities for open communication, giving feedback and explanations, because only the subordinates are fully aware of their circumstances. Previous studies show that favourable subjective allocations can signal support and benevolent intentions (Voußem et al., 2016). This suggests that the adoption of subjective evaluation can be positively related to perceived interactional justice.

However, subjective performance evaluation, being based mainly on human judgement, can be biased in several ways. First, when facing high workloads with scarce personal resources, evaluators may prioritise core organizational targets and 
the completion of incentivised tasks (Schmidt \& DeShon, 2007). Other tasks, such as subordinate evaluation and justice, are neglected, as they are considered less important to the success of the employees and their organizations (Sherf, 2016). Supervisors tend not to put enough effort into giving feedback and not to provide sufficient explanations or clarifications of misunderstandings to their subordinates regarding their evaluations.

Second, supervisors' assessments can be unconsciously influenced by cognitive bias, meaning that they may treat their subordinates differently from one another. According to attribution theory (Feldman, 1981), a supervisor makes attributions about his/her subordinates and assigns them to categories. This categorisation produces a bias in performance evaluation because some information is irrelevant, yet salient and influences subjective assessments. In addition, subjective assessments can be influenced by favouritism and likeability (Bol \& Smith, 2011; Fisher et al., 2005; Moers, 2005). A supervisor may have more positive/negative sentiments towards more/less charismatic subordinates (Scott et al., 2007). Positive sentiments lead to respectful and courteous treatment and appropriate feedback, while negative sentiments can cause prejudicial communication. When employees receive less equal and respectful treatment from their supervisors than their co-workers, they are likely to feel that their supervisors do not respect or act benevolently enough towards them.

Finally, the opportunities for communication and feedback that come with subjective evaluation do not always have positive effects on perceived justice. The feedback process can be perceived as another task to be done, which leads to anxiety for many employees (Baker et al., 2013). It may also focus on how one is not performing well or not reaching predetermined goals (Selden \& Sowa, 2011). Overall, the feedback process can lead to undesirable outcomes such as one-sided conversations, misunderstanding, greater stress levels, and competition, which subsequently reduces the perceived interactional justice (DeGregorio \& Fisher, 1988; Gravina \& Siers, 2011; Mulder, 2013).

The above discussion suggests that employees are only likely to have favourable interactional justice perceptions if supervisors show truthfulness, concern, and goodwill in their assessments. This happens when supervisors are considerate of subordinates' needs and interests and act benevolently towards them. On the contrary, if subjective evaluation comes with bias and favouritism, it is a great source of interactional unfairness.

Given the cultural values of Vietnam, we predict that a greater level of subjective evaluation may be associated with lower perceived interactional justice. As there is high power distance - a great degree of inequality between supervisors and subordinates, supervisors are generally decision-makers and subordinates are not expected to provide their opinions (Kirkman et al., 2006). In such a context, the feedback process, if applicable, is most likely considered to be a one-sided, critical conversation rather than an opportunity for information exchange. Hence, subjective assessments are given with little information-sharing or explanation, which decreases the chance that employees feel respected and heard. A lack of explanations and communication may increase the level of information asymmetry, opening the door even wider for favouritism and bias. The collectivistic culture may also amplify the negative effects 
of biased ratings on perceived interactional justice, because individuals who seek common interest and collective goals tend to build greater resentment towards their supervisors' misjudgment and disrespect. Correspondingly, we form the following hypothesis for the emerging context:

H1 Subjectivity in performance evaluation practices is negatively related to perceptions of interactional justice.

\subsection{The relationship between perceived interactional justice and the other two justice dimensions}

\subsubsection{Interactional justice and procedural justice}

People develop their perceptions of justice based on the subsequence of information they receive (Van den Bos et al., 1997). Because evaluation procedures are not always transparent and straightforward, employees are unable to perceive those procedures directly. Meanwhile, they can directly observe the communication and treatment from their supervisor who is responsible for the performance assessment. They also tend to routinely identify the person(s) responsible for injustice if it happens (Folger \& Cropanzano, 1998; Liu et al., 2013). Put differently, people perceive interactional justice on a daily basis in virtually any supervisor-subordinate encounter, including communication during the evaluation process (Bies, 2005). Hence, we predict that perceptions of interactional justice come before perceived procedural justice.

Furthermore, we argue that how employees think about the procedures is influenced by how supervisors enact resource allocation procedures and treat the employees (Liu et al., 2013). Employees perceive positive interactional justice when their supervisors can use communication as opportunities for information sharing, reasonable explanations, and clarification of doubts and misunderstanding (Bies \& Shapiro, 1988; Lau \& Tan, 2006). According to expectancy theory, adequate communication can enhance employees' certainty about the mission and goals to be achieved (Rosen et al., 2006). In addition, employees who are given a chance to communicate their views to their supervisors tend to believe that they can influence the process. As a result, the communication will make the evaluation process appear more transparent, thus increasing perceived accuracy and reducing potential biases (Hartmann \& Slapničar, 2012). In addition, respectful treatment can enhance the sense of self-worth and group standing, thereby promoting employees' perceived procedural justice (Tyler, 1989; Tyler \& Lind, 1992). Overall, and consistent with Cohen-Charash and Spector (2001), we argue that interactional justice is an antecedent to procedural justice.

Prior research provides evidence about the positive role of interactional justice perceptions across cultures (Leung et al., 2001; Morris \& Leung, 2000). Kim and Leung (2007) find that interactional justice positively shapes overall fairness perceptions across their sample of Americans, Japanese, Chinese and Koreans. A lack of interactional justice perceptions, by contrast, is linked to workplace deviant 
behaviours, regardless of different levels of power distance. That being said, we expect to find a positive relationship between interactional justice and procedural justice perceptions in the context of emerging economies, which is the same manner in Western cultures. A positive perceived interactional justice is likely to enhance perceived accuracy and foster a favourable perception of procedural justice in emerging economies, and vice versa. We propose the following hypothesis:

H2 Interactional justice perception is positively related to procedural justice perception.

\subsubsection{Interactional justice and distributive justice}

In line with Cohen-Charash and Spector (2001), we argue that interactional justice perception is also an antecedent to distributive justice perception for the following reasons. First, fairness judgements are more strongly influenced by information received at an earlier stage of interaction with the authority figure than by information received subsequently (Van den Bos et al., 1997). Since information about supervisors' treatment is usually available before any rewards are given out, interactional justice perceptions may be perceived earlier than distributive justice perceptions.

Second, perceived interactional justice influences employees' trust in their supervisors, which in turn affects their distributive justice perceptions. If the supervisors show consideration for their subordinates' needs and interests and refrain from exploiting others, the subordinates tend to see the supervisors as being trustworthy (Whitener et al., 1998). The high level of trust allows the employees to have confidence in the supervisors' knowledge and competencies to make better decisions regarding evaluation outcomes (Yang et al., 2009). By contrast, a low level of trust due to low perceived interactional justice might lead to anxiety and suspicion about any outcome decisions the superiors make.

Third, employees who perceive a greater level of interactional justice by having respectful and sufficient communication are more likely to be satisfied with their outcomes. According to expectancy theory, employees who get more feedback can better understand good performance standards and can use the feedback to improve their performance (Rosen et al., 2006). As a result, they can have more favourable outcomes, thus more positive justice perceptions. Even when the outcomes are unfavourable to the employees, the dissatisfaction can be alleviated by receiving adequate feedback and explanations, such as those related to claims of incompetence, budgetary constraints, restrictions due to company policy, and inconsistent company norms (Beugré, 2007; Bies et al., 1988; Libby, 1999).

We have discussed in the previous section that the links of justice forms should be similar across cultures. Kim and Leung (2007) describe that interactional justice perception is positively related to overall perceived justice in multiple countries of diverse cultures. Consistent with this, Leung et al. (2001) indicate positive effects of perceived interactional justice on decision outcomes in China. Hence, we expect to find a similar relationship between interactional justice perceptions and distributive justice perceptions across contexts. 
From the above discussion, we develop the following hypothesis:

H3 Interactional justice perception is positively related to distributive justice perception.

\subsection{Subjectivity in performance evaluation and procedural justice perceptions: mediated by interactional justice perceptions}

Thus far, we have hypothesised that subjectivity in performance evaluation influences employee interactional justice perceptions. We also suggested that interactional justice perceptions come before procedural justice perceptions. Therefore, we expect that the relationship between subjective evaluation and procedural justice perceptions is indirect through interactional justice perceptions.

Subjectivity in performance evaluation is enacted and influenced by the personal judgement of a supervisor. Hence, it should be the most relevant to interactional justice which concerns the fairness of the treatment and communication towards employees (rather than procedural or distributive justice). We expect that employees tend to attribute the fairness of subjective evaluation primarily to their supervisors, who have significant decision-making roles in the assessments. If subjective judgements can enable feedback and show the supervisors' consideration and benevolence, the employees are likely to feel respected and heard, and perceive positive interactional justice perceptions. This, in turn, makes the performance evaluation procedures appear more transparent and less biased, which increases perceived procedural justice. On the contrary, if the supervisors' assessments are influenced by bias and favouritism, the employees tend to attribute the injustice to the supervisors responsible (Folger \& Cropanzano, 1998). A biased evaluation can signal disrespect and interpersonal malevolence from the supervisors, which degrade employees' sense of interactional justice. Consequently, decreased interactional justice is related to decreased procedural justice perception, as the subordinates become less convinced that performance evaluation procedures are applied consistently and appropriately. Our prediction is consistent with suggestions by Colquitt (2001) and Moorman (1991) that a supervisor's evaluation may be even more related to perceived interactional justice than to the other forms of justice.

In the case of Vietnam and other emerging economies, as described in Sect. 3.1, we predict interactional justice perceptions to be lower when there is a greater subjective evaluation. As a result, that brings out decreased procedural justice perceptions. Accordingly, we propose the following hypothesis:

H4 Interactional justice perception mediates the relationship between subjectivity in performance evaluation and procedural justice perceptions. Specifically, a higher level of subjectivity significantly decreases perceived interactional justice, and in turn relates to decreased perceived procedural justice. 


\subsection{Subjectivity in performance evaluation and distributive justice perceptions: mediated by interactional justice perceptions}

We have suggested that subjectivity in performance evaluation affects interactional justice perceptions. In addition, interactional justice perception is expected to be an antecedent to distributive justice perception. Thus, we argue that interactional justice could explain the mechanism through which subjective evaluation is related to perceptions of distributive justice. Specifically, if the subjective evaluation shows truthfulness, benevolence, and goodwill from supervisors and enhances employee interactional justice perceptions, the employees tend to see their supervisors as trustworthy (Whitener et al., 1998). This, in turn, allows the employees to be confident of the supervisors' ability to make better decisions related to evaluation outcomes; as a result, they will perceive high levels of distributive justice (Yang et al., 2009). By contrast, if the employees observe biases from their supervisors' treatments and judgements, they are inclined to perceive a low level of interactional justice. That lowers the employees' perceived distributive justice because they become convinced that their outcomes are relatively undervalued compared to their effort and that of their peers (Bol et al., 2016).

Given the Vietnamese nationals' high power distance and collectivism, the latter is likely to apply, as discussed earlier in Sect. 3.1. We expect a greater level of subjectivity in performance evaluation to relate to a lower level of perceived interactional justice, which leads to lower distributive justice perceptions. Formally, we hypothesise:

H5 Interactional justice perception mediates the relationship between subjectivity in performance evaluation and distributive justice perceptions. Specifically, a higher level of subjectivity negatively affects perceived interactional justice, and in turn relates to decreased perceived distributive justice.

\section{Methodology}

\subsection{Sample}

The sample for this study was obtained from the Vietnam Chamber of Commerce and Industry (VCCI), a national entity that brings together and represents the business community in Vietnam. The VCCI database was selected because it included firms of various sizes and industries. The large size of the database necessitated limiting the survey to three selected cities: Hanoi, Ho Chi Minh City, and Danang, the country's main economic hubs.

Following prior work, we addressed organizations with more than 20 employees, because they were more likely to utilise proper performance evaluation practices and an associated reward system. The respondents to our study were middle-level managers (such as divisional or department managers), whose tasks were usually multi-dimensional and subject to diverse performance evaluation practices, including subjective evaluation. 


\subsection{Survey design and data collection}

We conducted a survey to collect data from our targeted participants. Before being launched, the questionnaire was pre-tested to assess the length and the comprehensibility of the English-Vietnamese translation (Dillman \& Groves, 2011; Morgan, 1990; Van der Stede et al., 2005). We also assessed the validity of the measurement instruments in the Vietnamese context. For this preliminary stage, we invited academics and practitioners from various business fields to take part, in order to receive comments from various perspectives. The questionnaire was continuously improved and modified during the pre-test process.

The survey instrument was web-based. An initial invitation email containing the relevant link was sent to the targeted participants in June 2017. A cover letter was included to provide a brief introduction to the main purposes of the research. It also gave assurances regarding the confidentiality of the responses, emphasising that only aggregate results would be published and used solely for academic purposes. We sought to make the recipients feel comfortable with taking part in the survey.

As suggested by Dillman and Groves (2011), we sent reminder emails three weeks after the initial email, and a second reminder was sent three weeks after that. In all, 163 managers completed the survey form from the 700 invitations that we sent. Following the removal of three disengaged responses that featured the same answers to almost all the questions, we had a final sample of 160 (for a response rate of $22 \%$ ).

\subsection{Measurement instrument}

\subsubsection{Subjectivity in performance evaluation (Subj)}

We measured subjectivity using a two-item scale adapted from Kruis (2010). Respondents were asked about the degree to which they thought their supervisors used subjective judgement to evaluate their performance. The respondents also rated the degree to which the supervisors determined salaries and bonuses using their discretion. Responses used a five-point Likert scale from 'not at all' (coded 1) to 'very much' (coded 5). Higher scores indicate higher levels of subjectivity in evaluating a middle manager's performance.

\subsubsection{Perceptions of procedural justice of the performance evaluation system (ProcJ)}

We assessed perceptions of procedural justice using direct measures, as recommended by Greenberg and Colquitt (2013). This direct approach involved asking respondents explicitly about their justice perceptions, rather than judging from implicit principles or elements of justice. Perceived procedural justice was measured using a three-item Likert scale adapted from Hartmann and Slapničar (2012) and McFarlin and Sweeney (1992). The scale addressed the extent to which the 
participants trusted the fairness of the evaluation system. Higher scores indicate that middle managers considered the performance evaluation process to be fairer.

\subsubsection{Perceptions of the distributive justice of the performance evaluation outcomes (DistrJ)}

A three-item instrument developed by Colquitt (2001) and Moorman (1991) was used to measure distributive justice perception. The respondents indicated whether they had received fair salaries and rewards for their effort, experience, and competence. Responses were rated on a five-point Likert scale from 'strongly disagree' (coded 1) to 'strongly agree' (coded 5). Higher scores indicate higher levels of distributive justice perception.

\subsubsection{Perceptions of the interactional justice of performance evaluation system (InterJ)}

The perception of interactional justice was measured with a five-item instrument developed by Colquitt (2001) and Moorman (1991). The participants addressed the extent to which their supervisors treated them with respect and politeness, and showed concern for their rights as employees. The other three items addressed the communication between participants and their supervisors. Respondents rated the extent to which they were provided with reasonable explanations and feedback about the procedures, and the degree to which their supervisors were frank and honest in their communication. A five-point Likert scale from 'strongly disagree' (coded 1) to 'strongly agree' (coded 5) was used, with higher scores reflecting greater levels of interactional justice perception.

\subsubsection{Control variables}

We controlled for three demographic variables: age, firm size and type of firm ownership. Age was indicated in years. Firm size was measured by a dummy variable with ' 1 ' for small and medium-sized firms (20-50 employees) and ' 2 ' for large firms (more than 50 employees). Ownership type was measured by a dummy variable with ' 1 ' for state-owned enterprises and ' 2 ' for other ownership types. Our statistical tests indicated that none of the control variables were significantly associated with our dependent variables.

\subsection{Descriptive analysis}

As recommended by Van der Stede et al. (2005), we tested for non-response bias by comparing early and late respondents in terms of the mean values of various demographic variables: age, gender, work and management experience, number of employees in the organization, and type of ownership. Four main variables (Subj, ProJ, DisJ, InterJ) were also compared. The results of the non-response bias test revealed no systematic differences for any of the variables, so there is no risk of 
non-response bias in the study. Table 1 presents the mean, standard deviation and percentage details for the demographic variables.

We used a covariance-based structural equation model (SEM) to test the hypotheses (Hair et al., 2014; Schumacher \& Lomax, 1996). This method is preferable over others (e.g. partial least square-PLS) because of its ability to estimate multiple and interrelated dependence relationships and deal with inherent errors (Hair et al., 2014, p. 547). It produces better estimates of the population parameters and is considered the best choice for obtaining accurate estimates, even when the sample is small (Chumney, 2013; Goodhue et al., 2012). The quality of the measurement model was assessed by exploratory factor analysis (EFA) and confirmatory factor analysis (CFA) for item reliability and validity. Tables 2 and 3 present the EFA results and the assessment from these tests.

The reliability of the constructs was assessed by Cronbach's alpha values. Reliability is how well 'individual items of a scale measure the same construct and thus are highly inter-correlated' (Hair et al., 2014, p. 123). As shown in Table 2, all these values are greater than 0.7 , which is a satisfactory indicator of reliability.

Convergent validity assesses 'the degree to which two measures of a same concept are correlated' (Hair et al., 2014, p. 123). The condition is satisfied when items load significantly on their corresponding latent variable (Sila, 2010). In Table 3, all standardised loading estimates are higher than 0.7 (except for "InterJ1" with loading value close to 0.6 ), which is satisfactory. Convergent validity was also evaluated by average variance extracted (AVE), which should be higher than 0.5, and construct reliability (CR), which should be 0.7 or above. Table 2 shows that all CR and AVE values indicate good convergence or internal consistency; thus, the convergent validity is satisfactory.

The second form of validity, discriminant validity, is 'the degree to which two conceptually similar concepts are distinct' (Hair et al., 2014, p. 124). Fornell and Larcker (1981) state that the condition of discriminant validity is satisfied when a construct's AVE is greater than all pair square correlations between the construct and other constructs in the model. Table 4 presents the correlations of the variables, and shows that the square root of the AVE for each variable is greater than the offdiagonal elements. Taken together, these results provide evidence of the convergent and discriminant validity of our scales.

It should be noted from Table 4 that three types of justice are highly correlated, which may raise issues about discriminant validity. However, the high correlations are quite predictable because they are sub-categories within organizational justice theory. The analysis has shown strong support for discriminant validity, suggesting that the high correlations among justice do not substantially affect our subsequent analysis and conclusions.

In addition, the CFA results indicate a good fit as follows: chi-square $=115.187$; df: 94; $p=0.068$; comparative fit index (CFI): 0.986; goodness-of-fit index (GFI): 0.92; root-mean-square error of approximation (RMSEA): 0.038. Model fit is typically inferred when the $p$-value is not significant (greater than 0.05), CFI and GFI are greater than 0.89, and RMSEA is lower than 0.05 (Hair et al., 2014, p. 584). 
Table 1 Respondents' background information

n

$\%$ or Mean (SD)

Panel A-Characteristics of managers

Gender

Male

Female

79

49.6

Age

25-30

57

31-40

61

41-50

51-59

Department

Sales

Accounting

Administration

HR

Production

Customer service

IT and technical

Others

Years of work experience

Years of management experience

Panel B-Characteristics of the firms

Number of employees

$$
50 \text { or below }
$$

More than 50

Sector of operation

Manufacturing

Trading

Transportation and construction

Banking or financial services

Education and training

Health services

Information and communication

Culture, sport or tourism service

Other sectors

Forms of ownership

$100 \%$ state-ownership

Stock equity with more than $50 \%$ state-owned

Stock equity with less than $50 \%$ state-owned

Stock equity of domestic investors

Private ownership

29

10.0

Joint venture between state and foreign investors

16

0.6

Joint venture between domestic and foreign investors
1

16
10.0 
Table 1 (continued)

\begin{tabular}{lll}
\hline & $n$ & $\%$ or Mean (SD) \\
\hline $100 \%$ foreign ownership & 37 & 23.1 \\
City & & \\
Hanoi & 33 & 20.6 \\
Danang & 65 & 40.6 \\
Ho Chi Minh City & 62 & 38.8 \\
\hline
\end{tabular}

\section{Results}

As stated earlier, our study proposes that interactional justice perception mediates the relationships between subjective evaluation and procedural justice perception. It also proposes that interactional justice perception is the mediator in the relationship between subjective evaluation and distributive justice perception.

We tested the mediation hypotheses following the mediation model of Baron and Kenny (1986). In the first step, the correlation between the independent variable (Subj) and the mediating variable (InterJ) was examined (path a). We also examined the association between the mediating variable InterJ and the dependent variables (ProJ and DisJ) in paths $b_{1}$ and $b_{2}$, respectively. The relationships between the independent variable and the dependent variables were also tested (path $\mathrm{c}_{1}$ and path $\mathrm{c}_{2}$ ). In the second step, we tested paths $\mathrm{c}_{1}$ and $\mathrm{c}_{2}$ again when controlling for the mediating variable. If the correlation between the independent variable and the dependent variable previously found to be significant is no longer statistically significant, it is referred to as full mediation. This implies that the relationship between the independent variable and the dependent variable unfolds through the mediator (Baron $\&$ Kenny, 1986). When both indirect and direct effects exist, the mediation effect is partial. The results are shown in Figs. 1 and 2.

The first phase of analysis shows statistical significance in all the direct effects (Fig. 1). Subj has a significant negative effect on InterJ (the coefficient of path a is $-0.23, p<0.01$ ). There is also a significant positive correlation between InterJ and ProcJ (the coefficient of path $b_{1}$ is $0.80, p<0.01$ ). The direct relationship between Subj and ProcJ is significant and negative (the coefficient of path $c_{1}$ is -0.24 , $p<0.01$ ). The significant results confirm $\mathrm{H} 1$ and $\mathrm{H} 2$, and offer initial support for $\mathrm{H} 4$.

As for the relationship paths between Subj and DistrJ, the coefficients between Subj and InterJ (path $a, \beta=-0.23$ ), InterJ and DistrJ (path $b_{2}, \beta=0.70$ ), and Subj and DistrJ (path $c_{2}, \beta=-0.29$ ) are all significant (at $p<0.01$ ) (see Fig. 1). The results confirm $\mathrm{H} 3$ and give initial support to $\mathrm{H} 5$. Even though we did not form a hypothesis regarding the relationship between procedural justice and distributive justice, we tested and found a positive association between them.

Figure 2 shows the results from the full model when InterJ (the mediator) is controlled for (second step). Mediation effects are interpreted as the strength of the indirect relationship between Subj and two dependent variables (ProcJ and DistrJ) when InterJ serves as the mediator. The sizes of the indirect effects (see 


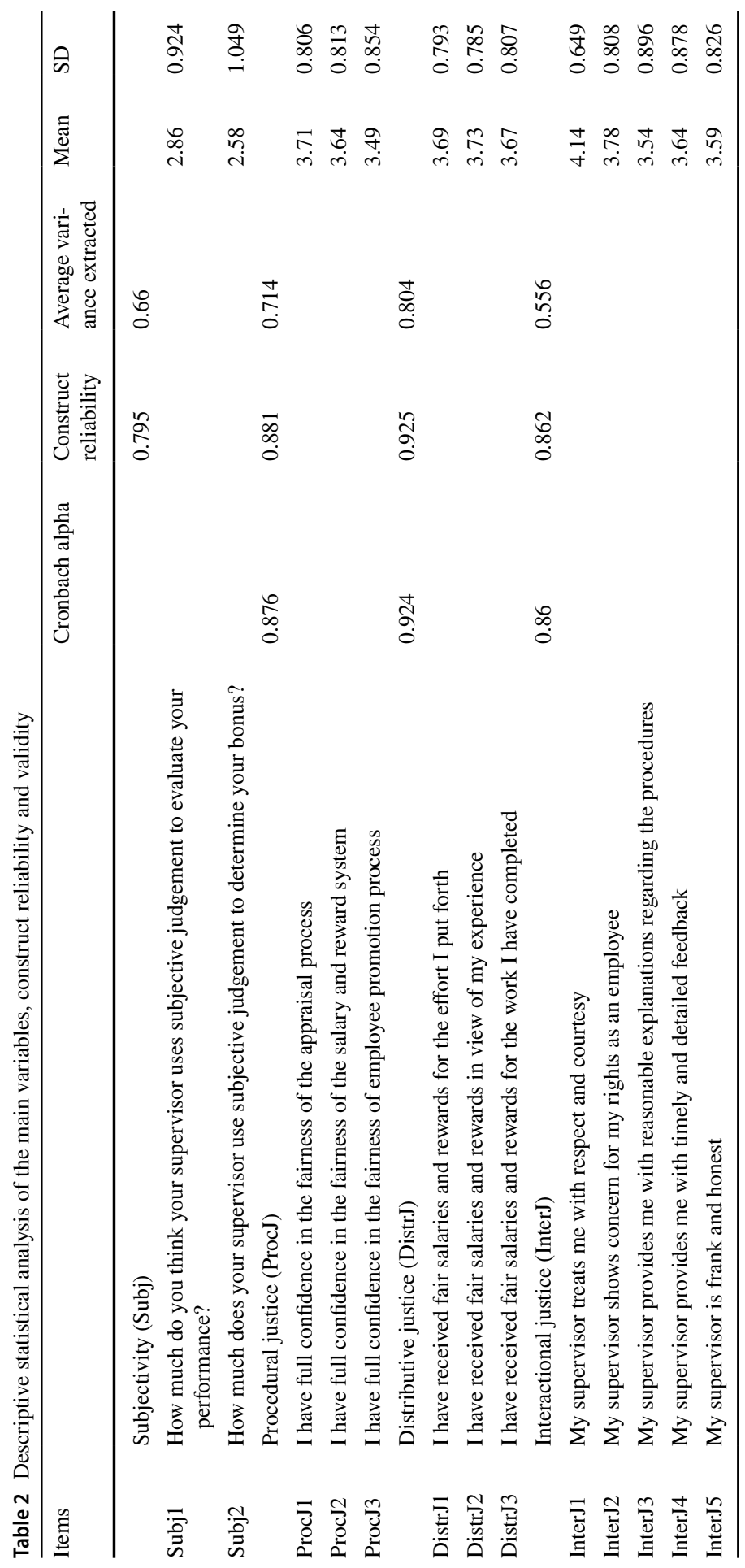




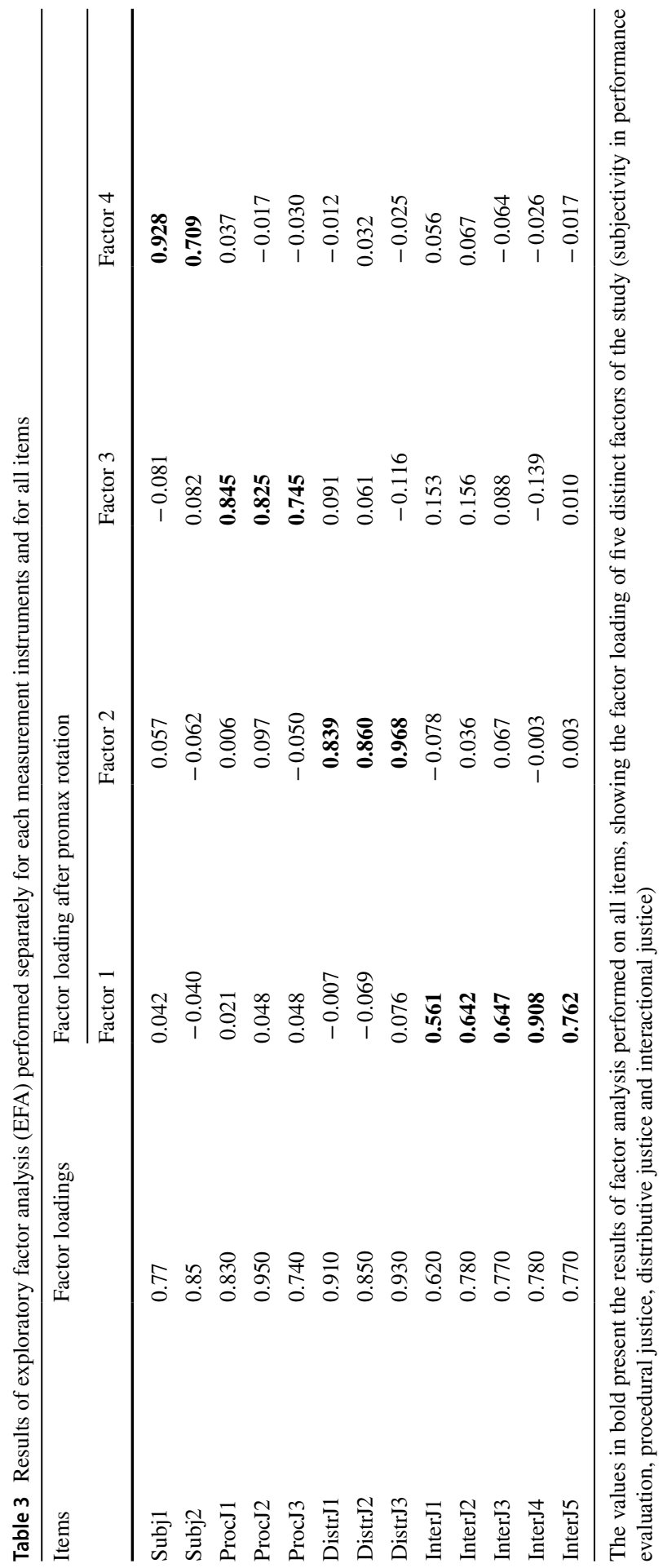


Table 4 Test of discriminant validity of each measurable variable

\begin{tabular}{|c|c|c|c|c|}
\hline & 1 & 2 & 3 & 4 \\
\hline 1. Subjectivity & 0.730 & & & \\
\hline $\begin{array}{l}\text { 2. Procedural } \\
\text { Justice }\end{array}$ & -0.204 & 0.848 & & \\
\hline $\begin{array}{l}\text { 3. Distributive } \\
\text { Justice }\end{array}$ & -0.195 & 0.646 & 0.899 & \\
\hline $\begin{array}{l}\text { 4. Interactional } \\
\text { Justice }\end{array}$ & -0.157 & 0.742 & 0.651 & 0.745 \\
\hline
\end{tabular}

Table 5) are based on the path coefficients in Fig. 2 (coefficients of path a $\times$ coefficients of path $b_{1}$ or $b_{2}$ ). We also examined adjusted $R^{2}$ values to obtain an estimate of the mediator's effect size.

In the full model, Subj has a significant correlation with InterJ, but it no longer has a significant effect on ProcJ $(p>0.05)$ (see Fig. 2). This indicates that InterJ has a full mediation effect on the relationship between Subj and ProcJ, since it eliminates their previous significant correlation (the indirect effect path coefficient is $-0.18, p<0.01, \mathrm{R}^{2}$ increased from 10 to $64.5 \%$ ) (see Table 5). Subj does not intrinsically affect ProcJ; it acts through the link of InterJ, thus H4 is supported. According to Zhao et al. (2010), the result implies that there is no mediating variable omitted between Subj and ProcJ.

InterJ also acts as the mediator in the relationship between Subj and DistrJ. Subj still has a significant direct effect on DistrJ in the full model (the path coefficient is $-0.12, p<0.1$ ), even though the effect is not as strong as previously in path $c_{2}$ of Fig. 1. It can be stated that InterJ has a partial mediating effect on the relationship between Subj and DistrJ (the indirect effect path coefficient is $-0.10, p<0.01, \mathrm{R}^{2}$ increased from 12 to 54.6\%) (see Table 5). This is defined by Zhao et al. (2010) as complementary mediation, in which the mediated effect $\left(a \times b_{2}\right)$ and direct effect $\left(c_{2}\right)$ both exist and point in the same direction; both are negative in this case. Hence, H5 is confirmed. When a greater level of Subj is applied, middle managers may doubt the consistency of treatment by their supervisors and perceive a lower level of interactional justice. The decreased interactional justice perception relates to decreased distributive justice; in other words, they think they are not fairly compensated for their performance.

To check the robustness of our model specification, we re-performed our analysis, including only participants from large organizations (with more than 50 employees). The results are almost identical, with a similar significance level for the paths, and qualitatively equivalent to those reported earlier. This provides assurance as to the robustness of our findings with respect to the size of the organizations in the sample. 


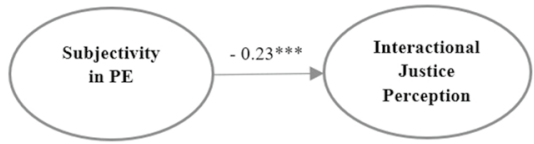

(a) First condition

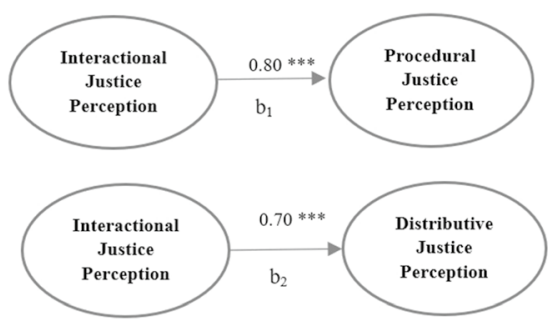

(b) Second condition
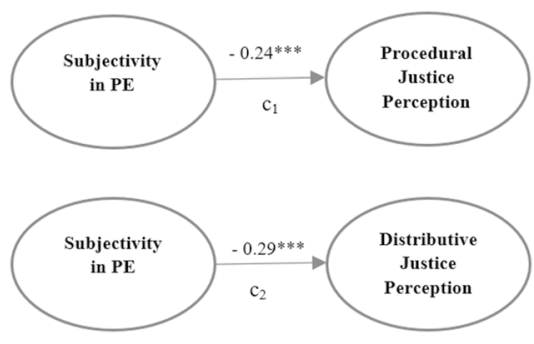

(c) Third condition

Notes: Significance level $\left({ }^{* * *} \mathrm{p}<0.001, * * \mathrm{p}<0.05,{ }^{*} \mathrm{p}<0.10\right)$

Fig. 1 Testing conditions of mediation model

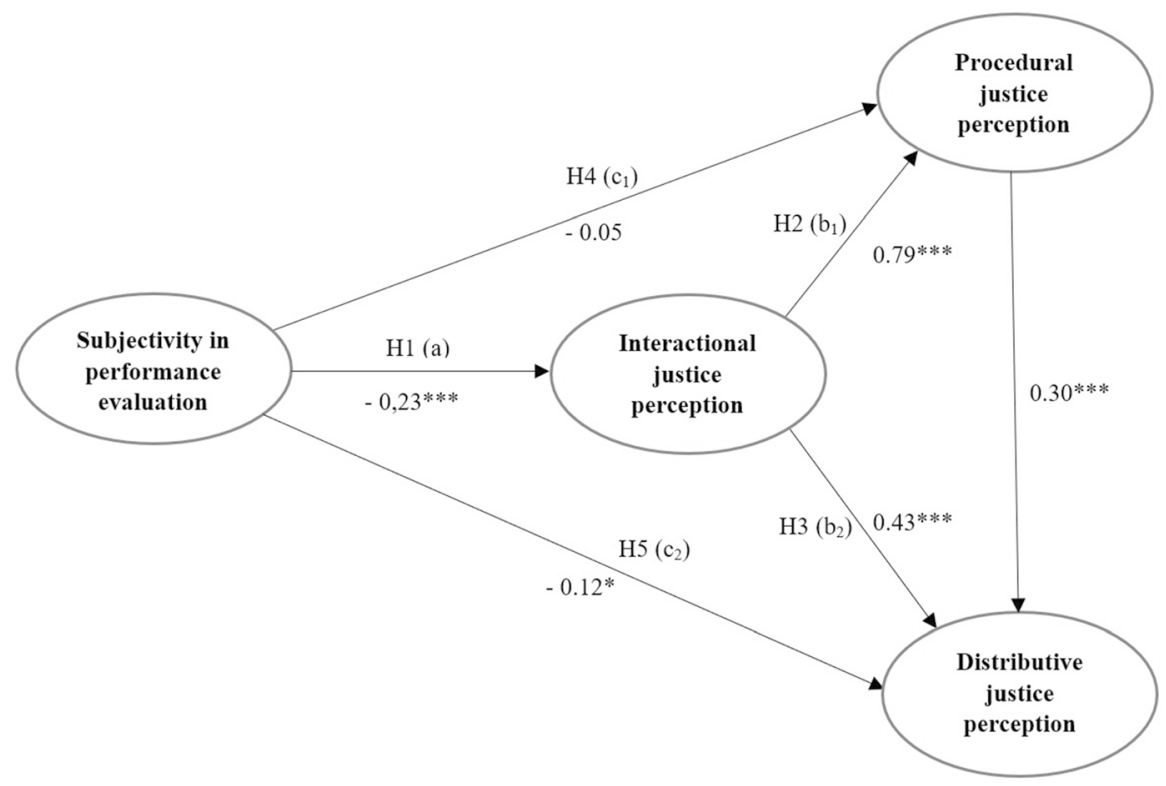

Notes: Significance level $\left(* * * \mathrm{p}<0.001, * * \mathrm{p}<0.05,{ }^{*} \mathrm{p}<0.10\right)$

Fig. 2 Structural model of subjectivity and the dimensions of justice perception 
Table 5 Testing mediation effects of interactional justice perception

\begin{tabular}{|c|c|c|c|c|c|}
\hline \multirow[t]{2}{*}{ Independent variable } & \multirow[t]{2}{*}{ Dependent variable } & \multicolumn{2}{|l|}{ Direct path } & \multicolumn{2}{|c|}{ Mediation path } \\
\hline & & Coefficient & $\mathrm{R}^{2}$ & Coefficient & $\mathrm{R}^{2}$ \\
\hline \multirow[t]{2}{*}{ Subjectivity } & Procedural justice & -0.057 & $10 \%$ & $-0.18 * * *$ & $64.50 \%$ \\
\hline & Distributive justice & $-0.12 *$ & $12 \%$ & $-0.10 * * *$ & $54.60 \%$ \\
\hline
\end{tabular}

Path (Subjectivity-Interactional justice-Procedural justice) $=-0.23 \times 0.79=-0.18$

Path (Subjectivity-Interactional justice-Distributive justice $)=-0.23 \times 0.43=-0.10$

\section{Discussion and conclusion}

One of the outcomes desired from any performance evaluation system is positive justice perceived by employees, which, in turn, enhances performance and inspires favourable work attitudes such as motivation and commitment (Kernan \& Hanges, 2002; Lau \& Moser, 2008). Positive perceived justice is also an important component for ethical management practices in organizations (Brown et al., 2005; Xu et al., 2016). This study investigates the effect of a component of a performance evaluation system - subjective evaluation-on three forms of justice perception. We aim to extend the literature by analysing the role of interactional justice perceptions as a critical mechanism underlying the impacts of subjective evaluation on procedural and distributive justice perceptions. The setting of the study involves performance evaluation systems in Vietnam as a representative of emerging economies, since there has been limited research in these contexts. We specifically examine the impact of two culture dimensions-power distance and individualism/collectivism (Hofstede, 1980)—because of their relevance to employees' reactions to control practices in organizations (Chow et al., 2001).

Results from our data supported our hypotheses that the negative effects of subjectivity in performance evaluation are more prominent than positive ones. We find that subjective evaluation is negatively associated with three dimensions of justice perception. This can be explained by the limitations in human judgements and individuals' personal resources. Subjectivity in performance evaluation practices, in any form, is heavily influenced by private 'mental' aspects (LaFave, 2008) or personal perception, beliefs, or experiences (Choon \& Embi, 2012). Therefore, it is subject to numerous biases and favouritism, which negatively affect the perceived justice of those middle managers being evaluated. In addition, supervisors' personal resources are limited and scarce. When they are expected to engage in multiple tasks including core technical and managerial tasks, they tend to prioritise core responsibilities, which usually result in their own desired outcomes (bonuses, promotions, and recognition). Management tasks related to interacting with subordinates, providing them with information and giving performance evaluations are often neglected (Sherf, 2016).

The results can be justified in the context of Vietnam as an emerging economy, a research setting that has been largely neglected in management accounting literature. In a high power distance culture, subjective assessments are given with little 
information sharing or explanations from employees, which may increase information asymmetry and the opportunity for favouritism. The collectivistic culture may also amplify the negative impact of biased ratings, since individuals who seek common interest and collective goals tend to build greater resentment towards misjudgment and disrespect. Nevertheless, our results are consistent with findings in advanced markets regardless of cultural differences (e.g. Bellavance et al., 2013; Van Rinsum \& Verbeeten, 2012).

More importantly, we find that interactional justice perception is a mediator in the relationship between subjective evaluation and procedural justice perceptions. People tend to attribute the fairness of subjective evaluation to supervisors who have significant decision-making roles in the assessments. Since procedural justice is not always straightforward, middle managers perceive it through the way their supervisors treat them. Similarly, the relationship between subjectivity in performance evaluation and perceptions of distributive justice is partially indirect through interactional justice perceptions. Subjectivity in performance evaluation has a negative effect on perceptions of interactional justice, which lowers employees' confidence in their supervisors' ability to make fair decisions on their evaluation outcomes.

Overall, our results advance our understanding of the complex interrelationships between subjective performance evaluation and the three dimensions of justice perception (e.g. Hartmann et al., 2010; Voußem et al., 2016). Furthermore, our research is one of the very few analyses on the effects of subjective evaluation on all three aspects of justice perceptions, as prior studies have mostly focused on perceived procedural justice and distributive justice. We take a different perspective and focus on the role of interactional justice perceptions towards supervisors' treatments. Second, the study answers the calls of Cohen-Charash and Spector (2001) for an indepth investigation of interactional justice perceptions. Our findings highlight that subjective evaluation influences justice perceptions due to the interactional justice perceived from the supervisors. The results also indicate the importance of studying organizational justice concepts as three distinct yet related dimensions. Finally, our study expands on the growing literature on performance evaluation practices and justice perceptions in emerging economies. It meets the call from Ezzamel and Xiao (2011) for richer literature across countries and contributes to the generalizability of organizational justice theories worldwide (Greenberg \& Colquitt, 2013).

Our study has managerial implications related to how subjective evaluation should be applied to improve justice perceptions and encourage ethical behaviour in organizations. First, the negative effect of subjective evaluation on justice perception does not automatically imply that subjectivity should be dropped from performance evaluation systems. Rather, it suggests that top management should consider the trade-off between the benefits and drawbacks of subjective elements in performance evaluation. Perhaps excessive subjectivity in performance evaluation should be avoided. More importantly, the mediating role of interactional justice perceptions suggests that subjective evaluation could be designed to enhance respectful treatment and quality of communication towards employees to be deemed fairer by the evaluated employees. In particular, an organizational feedback-oriented culture could be implemented to provide detailed and timely feedback along with rewards or punishments to employees (Levy \& Williams, 2004; London \& Smither, 2002). 
Superiors should explain performance assessments and outcomes to employees in a respectful and transparent manner (Gupta \& Kumar, 2013). Adequate communication is meant to enhance the quality of feedback given in the organization, to increase the acceptance of feedback, and to make both evaluators and evaluatees feel comfortable in the process (London, 2003, p. 231; Rosen et al., 2006). Additionally, it may be worthwhile to place a greater emphasis on the competence of management teams so that they can communicate and produce feedback effectively (Pitkänen \& Lukka, 2011).

There are several limitations to our study. First, it was carried out in Vietnam, so any generalisation of our results to other settings should be performed with caution. Second, the measurement instruments were based on studies in English. Despite great efforts to ensure the accuracy and relevance of the English-Vietnamese translation, it is nevertheless possible that differences still exist between the English and Vietnamese versions. Such differences could introduce bias to the survey. Third, we did not ask the respondents to identify their organizations because we wanted to ensure their confidentiality and obtain a higher response rate. Hence, there might have been more than one respondent from some organizations, as the questionnaire was sent to several middle managers of each firm. This too may have led to some minor bias in the analysis.

Future studies could further examine the specific organizational circumstances that affect the relationship between subjectivity in performance evaluation and perceived interactional justice, as the relationship is prone to be influenced by contextual factors and the characteristics of those involved. In addition, since we only examined subjectivity as a whole, it might be fruitful to explore particular aspects of subjectivity in-depth, such as the use of subjective measures, flexibility in the weighting of certain performance measures, and ex-post discretional judgement. Finally, perceived interactional justice only has a partial mediating effect on the relationship between subjectivity and perceived distributive justice. This suggests the possible existence of some omitted mediators, which further studies can address.

Acknowledgements The authors acknowledge with thanks the valuable comments and guidance from editor Thomas Günther and two anonymous reviewers. We are grateful to Anne-Marie Kruis for her suggestions and comments on the questionnaire we used. We would also like to thank James Gaskin for his very useful online guidelines and video tutorials of AMOS. In addition, the authors acknowledge with gratitude the comments of participants in the Finnish Accounting Tutorial (2016), Management Control Association Doctoral Colloquium (2016), ACMAR Doctoral Colloquium (2018), the Management Control Association Symposium in Nice (2018) and research seminars at Oulu Business School (Finland). Thuy-Van Tran gratefully acknowledges the research funding support from Oulu University Scholarship Foundation.

Funding Open access funding provided by University of Oulu including Oulu University Hospital.

Open Access This article is licensed under a Creative Commons Attribution 4.0 International License, which permits use, sharing, adaptation, distribution and reproduction in any medium or format, as long as you give appropriate credit to the original author(s) and the source, provide a link to the Creative Commons licence, and indicate if changes were made. The images or other third party material in this article are included in the article's Creative Commons licence, unless indicated otherwise in a credit line to the material. If material is not included in the article's Creative Commons licence and your intended use is not permitted by statutory regulation or exceeds the permitted use, you will need to obtain permission 
directly from the copyright holder. To view a copy of this licence, visit http://creativecommons.org/licen ses/by/4.0/.

\section{References}

Ashkanasy, N. M. (2011). International happiness: A multilevel perspective. Academy of Management Perspectives, 25(1), 23-29

Baiman, S., \& Rajan, M. V. (1995). The informational advantages of discretionary bonus schemes. Accounting Review, 70(4), 557-579

Baker, A., Perreault, D., Reid, A., \& Blanchard, C. M. (2013). Feedback and organizations: Feedback is good, feedback-friendly culture is better. Canadian Psychology/Psychologie Canadienne, 54(4), 260-268

Baker, G., Gibbons, R., \& Murphy, K. J. (1994). Subjective performance measures in optimal incentive contracts. The Quarterly Journal of Economics, 109(4), 1125-1156

Baron, R. M., \& Kenny, D. A. (1986). The moderator-mediator variable distinction in social psychological research: Conceptual, strategic, and statistical considerations. Journal of Personality and Social Psychology, 51(6), 1173-1182

Bellavance, F., Landry, S., \& Schiehll, E. (2013). Procedural justice in managerial performance evaluation: Effects of subjectivity, relationship quality, and voice opportunity. The British Accounting Review, 45(3), 149-166

Beugré, C. D. (2007). A cultural perspective of organizational justice. New York: IAP.

Bies, R., \& Moag, R. (1986). Interactional justice: Communication criteria of fairness. In R. J. Lewicki, B. H. Sheppard \& M. H. Bazerman (Eds.), Research on Negotiations in Organizations (pp. 43-55). Greenwich, CT: JAI Press

Bies, R. J. (2005). Are procedural justice and interactional justice conceptually distinct? In J. Greenberg \& J. A. Colquitt (Eds.), Handbook of organizational justice (pp. 85-112). Mahwah: Lawrence Erlbaum Associates Publishers.

Bies, R. J., \& Shapiro, D. L. (1988). Voice and justification: Their influence on procedural fairness judgments. Academy of Management Journal, 31(3), 676-685

Bies, R. J., Shapiro, D. L., \& Cummings, L. L. (1988). Causal accounts and managing organizational conflict: Is it enough to say it's not my fault? Communication Research, 15(4), 381-399

Bol, J. C. (2008). Subjectivity in compensation contracting. Journal of Accounting Literature, 27, 1-27

Bol, J. C. (2011). The determinants and performance effects of managers' performance evaluation biases. The Accounting Review, 86(5), 1549-1575

Bol, J. C., Kramer, S., \& Maas, V. S. (2016). How control system design affects performance evaluation compression: The role of information accuracy and outcome transparency. Accounting, Organizations and Society, 51, 64-73

Bol, J. C., \& Smith, S. D. (2011). Spillover effects in subjective performance evaluation: Bias and the asymmetric influence of controllability. The Accounting Review, 86(4), 1213-1230

Brockner, J., Ackerman, G., Greenberg, J., Gelfand, M. J., Francesco, A. M., Chen, Z. X., \& Kirkman, B. L. (2001). Culture and procedural justice: The influence of power distance on reactions to voice. Journal of Experimental Social Psychology, 37(4), 300-315

Brown, M. E., Treviño, L. K., \& Harrison, D. A. (2005). Ethical leadership: A social learning perspective for construct development and testing. Organizational Behavior and Human Decision Processes, 97(2), 117-134

Byrne, Z. S., Pitts, V. E., Wilson, C. M., \& Steiner, Z. J. (2012). Trusting the fair supervisor: The role of supervisory support in performance appraisals. Human Resource Management Journal, 22(2), 129-147

Chang, E., \& Hahn, J. (2006). Does pay-for-performance enhance perceived distributive justice for collectivistic employees? Personnel Review, 35(4), 397-412

Cheng, M. M., \& Coyte, R. (2014). The effects of incentive subjectivity and strategy communication on knowledge-sharing and extra-role behaviours. Management Accounting Research, 25(2), $119-130$ 
Choon, L. K., \& Embi, M. A. (2012). Subjectivity, organizational justice and performance appraisal: Understanding the concept of subjectivity in leading towards employees' perception of fairness in the performance appraisal. Procedia-Social and Behavioral Sciences, 62, 189-193

Chow, C. W., Lindquist, T. M., \& Wu, A. (2001). National culture and the implementation of highstretch performance standards: An exploratory study. Behavioral Research in Accounting, 13(1), 85-109

Chow, C. W., Van der Stede, \& Wim, A. (2006). The use and usefulness of nonfinancial performance measures. Management Accounting Quarterly, 7(3), 1-8

Chumney, F. L.(2013). Structural equation models with small samples: A comparative study of four approaches. Doctoral dissertation, University of Nebraska-Lincoln, Lincoln, NE. Retrieved from: http://digitalcommons.unl.edu/cehsdiss/189.

Cohen, A., \& Avrahami, A. (2006). The relationship between individualism, collectivism, the perception of justice, demographic characteristics and organisational citizenship behaviour. The Service Industries Journal, 26(8), 889-901

Cohen-Charash, Y., \& Spector, P. E. (2001). The role of justice in organizations: A meta-analysis. Organizational Behavior and Human Decision Processes, 86(2), 278-321

Colquitt, J. A. (2001). On the dimensionality of organizational justice: A construct validation of a measure. Journal of Applied Psychology, 86(3), 386-400

Colquitt, J. A., Conlon, D. E., Wesson, M. J., Porter, C. O., \& Ng, K. Y. (2001). Justice at the millennium: A meta-analytic review of 25 years of organizational justice research. Journal of Applied Psychology, 86(3), 425-445

Colquitt, J. A., \& Greenberg, J. (2003). Organizational justice: A fair assessment of the state of the literature. In J. Greenberg (Eds.), Organizational behavior: The state of the science (2nd ed., pp. 165-210). Mahwah, NJ: Erlbaum.

Cropanzano, R., \& Greenberg, J. (1997). Progress in organizational justice: Tunneling through the maze. International Review of Industrial and Organizational Psychology, 12, 317-372

DeGregorio, M. B., \& Fisher, C. D. (1988). Providing performance feedback: Reactions to alternate methods. Journal of Management, 14(4), 605-616

Dillman, D., \& Groves, B. (2011). Internet, mail and mixed-mode surveys: The tailored design method. Survey Research, 34(833), 635

Du, J., \& Choi, J. N. (2010). Pay for performance in emerging markets: Insights from china. Journal of International Business Studies, 41(4), 671-689

Erdogan, B., \& Liden, R. C. (2006). Collectivism as a moderator of responses to organizational justice: Implications for leader-member exchange and ingratiation. Journal of Organizational Behavior: The International Journal of Industrial, Occupational and Organizational Psychology and Behavior, 27(1), 1-17

Ezzamel, M., \& Xiao, J. Z. (2011). Accounting in transitional and emerging market economies. European Accounting Review, 20(4), 625-637

Feldman, J. M. (1981). Beyond attribution theory: Cognitive processes in performance appraisal. Journal of Applied Psychology, 66(2), 127-148

Fisher, J. G., Maines, L. A., Peffer, S. A., \& Sprinkle, G. B. (2005). An experimental investigation of employer discretion in employee performance evaluation and compensation. The Accounting Review, 80(2), 563-583

Folger, R., \& Cropanzano, R. (1998). Organizational justice and human resource management (Vol 7). Thousand Oaks: Sage.

Folger, R., \& Konovsky, M. A. (1989). Effects of procedural and distributive justice on reactions to pay raise decisions. Academy of Management Journal, 32(1), 115-130

Folger, R., \& Skarlicki, D. P. (2008). The evolutionary bases of deontic justice. In Gililand SW, Steiner DD, Skarlicki DP (Eds.), Research in social issues in management: Justice, morality, and social responsibility (pp. 29-62). Greenwich, CT: Information Age Publishing

Fornell, C., \& Larcker, D. F. (1981). Structural equation models with unobservable variables and measurement error: Algebra and statistics. Journal of Marketing Research, 18(1), 382-388.

Fortin, M. (2008). Perspectives on organizational justice: Concept clarification, social context integration, time and links with morality. International Journal of Management Reviews, 10(2), 93-126

Frederiksen, A., Lange, F., \& Kriechel, B. (2017). Subjective performance evaluations and employee careers. Journal of Economic Behavior \& Organization, 134, 408-429

Gibbs, M., Merchant, K. A., Van der Stede, W. A., \& Vargus, M. E. (2004). Determinants and effects of subjectivity in incentives. The Accounting Review, 79(2), 409-436 
Golman, R., \& Bhatia, S. (2012). Performance evaluation inflation and compression. Accounting, Organizations and Society, 37(8), 534-543

Gomez-Mejia, L. R., Balkin, D. B., \& Cardy, R. L. (2007). Managing human resources. Englewood Cliffs: Pearson/Prentice Hall.

Goodhue, D. L., Lewis, W., \& Thompson, R. (2012). Does PLS have advantages for small sample size or non-normal data? Mis Quarterly, 36(3), 891-1001

Gravina, N. E., \& Siers, B. P. (2011). Square pegs and round holes: Ruminations on the relationship between performance appraisal and performance management. Journal of Organizational Behavior Management, 31(4), 277-287

Greenberg, J. (1987). A taxonomy of organizational justice theories. Academy of Management Review, 12(1), 9-22

Greenberg, J. (2001). Studying organizational justice cross-culturally: Fundamental challenges. International Journal of Conflict Management, 12(4), 365-375

Greenberg, J., \& Colquitt, J. A. (2013). Handbook of organizational justice. London: Psychology Press.

Gupta, V., \& Kumar, S., (2013). Impact of performance appraisal justice on employee engagement: A study of Indian professionals. Employee Relations, 35(1), 61-78

Hair, J. F., Black, W. C., Babin, B. J., \& Anderson, R. E. (2014). Multivariate data analysis: Pearson new international edition. Essex: Pearson Education Limited.

Hartmann, F., Naranjo-Gil, D., \& Perego, P. (2010). The effects of leadership styles and use of performance measures on managerial work-related attitudes. European Accounting Review, 19(2), 275-310

Hartmann, F., \& Slapničar, S. (2012). The perceived fairness of performance evaluation: The role of uncertainty. Management Accounting Research, 23(1), 17-33

Hempel, P. S. (2001). Differences between Chinese and Western managerial views of performance. Personnel Review, 30(2), 203-226

Hofstede, G. (1980). Culture and organizations. International Studies of Management \& Organization, 10(4), 15-41

Hofstede, G., Hofstede, G. J., \& Minkov, M. (2010). Cultures and organizations: Software of the mind. Revised and expanded (3rd ed.). New York: McGraw-Hill.

Höppe, F., \& Moers, F. (2011). The choice of different types of subjectivity in CEO annual bonus contracts. The Accounting Review, 86(6), 2023-2046

Hopwood, A. G. (1972). An empirical study of the role of accounting data in performance evaluation. Journal of Accounting Research, 47, 156-182

Ittner, C. D., Larcker, D. F., \& Meyer, M. W. (2003). Subjectivity and the weighting of performance measures: Evidence from a balanced scorecard. The Accounting Review, 78(3), 725-758

Kelly, K. O., Webb, R. A., \& Vance, T. (2015). The interactive effects of ex post goal adjustment and goal difficulty on performance. Journal of Management Accounting Research, 27(1), 1-25

Kernan, M. C., \& Hanges, P. J. (2002). Survivor reactions to reorganization: Antecedents and consequences of procedural, interpersonal, and informational justice. Journal of Applied Psychology, $87(5), 916$

Kim, T., \& Leung, K. (2007). Forming and reacting to overall fairness: A cross-cultural comparison. Organizational Behavior and Human Decision Processes, 104(1), 83-95

Kirkman, B. L., Lowe, K. B., \& Gibson, C. B. (2006). A quarter century of culture's consequences: A review of empirical research incorporating Hofstede's cultural values framework. Journal of International Business Studies, 37(3), 285-320

Krishnan, R., Luft, J. L., \& Shields, M. D. (2005). Effects of accounting-method choices on subjective performance-measure weighting decisions: Experimental evidence on precision and error covariance. The Accounting Review, 80(4), 1163-1192

Kruis, A. (2010). Survey on design and use of management control systems. Nyenrode Business Universiteit.

LaFave, S. (2008). Thinking critically about the subjective and objective distinction. Retrieved September, 28, 2011 from WVC Philosophy Department: http://instruct.westvalley.edu/lafave/subjective_ objective.html

Lam, S. S., Schaubroeck, J., \& Aryee, S. (2002). Relationship between organizational justice and employee work outcomes: A cross-national study. Journal of Organizational Behavior, 23(1), 1-18

Lau, C. M., \& Moser, A. (2008). Behavioral effects of nonfinancial performance measures: The role of procedural fairness. Behavioral Research in Accounting, 20(2), 55-71 
Lau, C. M., \& Oger, B. (2012). Behavioral effects of fairness in performance measurement and evaluation systems: Empirical evidence from France. Advances in Accounting, 28(2), 323-332

Lau, C. M., \& Sholihin, M. (2005). Financial and nonfinancial performance measures: How do they affect job satisfaction? The British Accounting Review, 37(4), 389-413

Lau, C. M., \& Tan, S. L. (2006). The effects of procedural fairness and interpersonal trust on job tension in budgeting. Management Accounting Research, 17(2), 171-186

Leung, K., Su, S., \& Morris, M. W. (2001). When is criticism not constructive? the roles of fairness perceptions and dispositional attributions in employee acceptance of critical supervisory feedback. Human Relations, 54(9), 1155-1187

Leventhal, G. S. (1980). What should be done with equity theory? In: Gergen KJ, Greenberg MS and Willis RH (eds), Social Exchange. Boston, MA: Springer US, 27-55.

Levy, P. E., \& Williams, J. R. (2004). The social context of performance appraisal: A review and framework for the future. Journal of Management, 30(6), 881-905

Libby, T. (1999). The influence of voice and explanation on performance in a participative budgeting setting. Accounting, Organizations and Society, 24(2), 125-137

Lind, E. A., \& Tyler, T. R. (1988). The social psychology of procedural justice. New York: Springer.

Lindquist, T. M. (1995). Fairness as an antecedent to participative budgeting: Examining the effects of distributive justice, procedural justice and referent cognitions on satisfaction and performance. Journal of Management Accounting Research, 7, 122-147

Liu, C., Yang, L., \& Nauta, M. M. (2013). Examining the mediating effect of supervisor conflict on procedural injustice-job strain relations: The function of power distance. Journal of Occupational Health Psychology, 18(1), 64-74

London, M. (2003). Job feedback: Giving, seeking, and using feedback for performance improvement. New York: Psychology Press.

London, M., \& Smither, J. W. (2002). Feedback orientation, feedback culture, and the longitudinal performance management process. Human Resource Management Review, 12(1), 81-100

Maaniemi, J., \& Hakonen, A. (2008). The reasons for and sources of employees' injustice experiences in the performance appraisal process. Reward Management-Facts and Trends in Europe, 188-210.

Mahama, H., \& Cheng, M. M. (2013). The effect of managers' enabling perceptions on costing system use, psychological empowerment, and task performance. Behavioral Research in Accounting, 25(1), 89-114

Marginson, D., McAulay, L., Roush, M., \& van Zijl, T. (2014). Examining a positive psychological role for performance measures. Management Accounting Research, 25(1), 63-75

Masterson, S. S., Lewis, K., Goldman, B. M., \& Taylor, M. S. (2000). Integrating justice and social exchange: The differing effects of fair procedures and treatment on work relationships. Academy of Management Journal, 43(4), 738-748

McFarlin, D. B., \& Sweeney, P. D. (1992). Distributive and procedural justice as predictors of satisfaction with personal and organizational outcomes. Academy of Management Journal, 35(3), 626-637

Moers, F. (2005). Discretion and bias in performance evaluation: The impact of diversity and subjectivity. Accounting, Organizations and Society, 30(1), 67-80

Moorman, R. H. (1991). Relationship between organizational justice and organizational citizenship behaviors: Do fairness perceptions influence employee citizenship? Journal of Applied Psychology, 76(6), 845-855

Morgan, F. W. (1990). Judicial standards for survey research: An update and guidelines. The Journal of Marketing, 54(1), 59-70.

Morris, M., \& Leung, K. (2000). Justice for all? Progress in research on cultural variation in the psychology of distributive and procedural justice. Applied Psychology, 49(1), 100-132

Mulder, R. H. (2013). Exploring feedback incidents, their characteristics and the informal learning activities that emanate from them. European Journal of Training and Development, 37(1), 49-71

Murphy, K. J., \& Oyer, P., (2001). Discretion in executive incentive contracts: Theory and evidence. Unpublished Manuscript

Ng, K., Koh, C., Ang, S., Kennedy, J. C., \& Chan, K. (2011). Rating leniency and halo in multisource feedback ratings: Testing cultural assumptions of power distance and individualism-collectivism. Journal of Applied Psychology, 96(5), 1033-1044

Otley, D. (1999). Performance management: A framework for management control systems research. Management Accounting Research, 10(4), 363-382 
Pitkänen, H., \& Lukka, K. (2011). Three dimensions of formal and informal feedback in management accounting. Management Accounting Research, 22(2), 125-137

Power, D., Schoenherr, T., \& Samson, D. (2010). The cultural characteristic of individualism/collectivism: A comparative study of implications for investment in operations between emerging Asian and industrialized Western countries. Journal of Operations Management, 28(3), 206-222

Prendergast, C., \& Topel, R. (1993). Discretion and bias in performance evaluation. European Economic Review, 37(2-3), 355-365

Rosen, C. C., Levy, P. E., \& Hall, R. J. (2006). Placing perceptions of politics in the context of the feedback environment, employee attitudes, and job performance. Journal of Applied Psychology, 91(1), 211-220

Schmidt, A. M., \& DeShon, R. P. (2007). What to do? The effects of discrepancies, incentives, and time on dynamic goal prioritization. Journal of Applied Psychology, 92(4), 928-941

Schumacher, R., \& Lomax, R. G. (1996). A beginner's guide to SEM. New Jersey: Mahwah.

Scott, B. A., Colquitt, J. A., \& Zapata-Phelan, C. P. (2007). Justice as a dependent variable: Subordinate charisma as a predictor of interpersonal and informational justice perceptions. Journal of Applied Psychology, 92(6), 1597-1609

Selden, S., \& Sowa, J. E. (2011). Performance management and appraisal in human service organizations: Management and staff perspectives. Public Personnel Management, 40(3), 251-264

Shen, J. (2004). International performance appraisals: policies, practices and determinants in the case of Chinese multinational companies. International Journal of Manpower, 25(6), 547-563

Sherf, E. N. (2016). Too busy to be fair? The effect of managers' perceived workload on their core technical performance and justice rule adherence. Doctoral Dissertation, University of Maryland, College Park. Retrieved from: https://drum.lib.umd.edu/handle/1903/18636

Sherman, A., \& Bohlander, G. (1988). Managing human resources. Cincinnati: South-Western Educational Publishing.

Sila, I. (2010). Do organisational and environmental factors moderate the effects of internet-based interorganisational systems on firm performance? European Journal of Information Systems, 19(5), 581-600

Silva, M. R., \& Caetano, A. (2014). Organizational justice: What changes, what remains the same? Journal of Organizational Change Management, 27(1), 23-40

Simons, T., \& Roberson, Q. (2003). Why managers should care about fairness: The effects of aggregate justice perceptions on organizational outcomes. Journal of Applied Psychology, 88(3), 432-443

Sokol, M., \& Oresick, R. (1986). Managerial performance appraisal. In R.A. Berk, (Ed.), Performance Assessment: Methods and Applications (pp. 376- 392). Baltimore: Johns Hopkins University Press.

Stammerjohan, W. W., Leach, M. A., \& Stammerjohan, C. A. (2015). The moderating effects of power distance on the budgetary participation-performance relationship. Advances in management accounting. Bingley: Emerald Group Publishing Limited.

Tyler, T. R. (1989). The psychology of procedural justice: A test of the group-value model. Journal of Personality and Social Psychology, 57(5), 830-838

Tyler, T. R., \& Lind, E. A. (1992). A relational model of authority in groups. Advances in experimental social psychology (pp. 115-191). New York: Elsevier.

Van den Bos, K., Lind, E. A., Vermunt, R., \& Wilke, H. A. (1997). How do I judge my outcome when I do not know the outcome of others? The psychology of the fair process effect. Journal of Personality and Social Psychology, 72(5), 1034-1046

Van der Kolk, B., \& Kaufmann, W. (2018). Performance measurement, cognitive dissonance and coping strategies: Exploring individual responses to NPM-inspired output control. Journal of Management Control, 29(2), 93-113

Van der Stede, W. A., Young, S. M., \& Chen, C. X. (2005). Assessing the quality of evidence in empirical management accounting research: The case of survey studies. Accounting, Organizations and Society, 30(7), 655-684

Van Rinsum, M., \& Verbeeten, F. H. (2012). The impact of subjectivity in performance evaluation practices on public sector managers' motivation. Accounting and Business Research, 42(4), 377-396

Virtanen, M., \& Elovainio, M. (2018). Justice at the workplace: A review. Cambridge Quarterly of Healthcare Ethics, 27(2), 306-315 
Viswesvaran, C., \& Ones, D. S. (2002). Examining the construct of organizational justice: A meta-analytic evaluation of relations with work attitudes and behaviors. Journal of Business Ethics, 38(3), 193-203

Voußem, L., Kramer, S., \& Schäffer, U. (2016). Fairness perceptions of annual bonus payments: The effects of subjective performance measures and the achievement of bonus targets. Management Accounting Research, 30, 32-46

Walumbwa, F. O., \& Lawler, J. J. (2003). Building effective organizations: Transformational leadership, collectivist orientation, work-related attitudes and withdrawal behaviours in three emerging economies. The International Journal of Human Resource Management, 14(7), 1083-1101

Warner, M. (2010). In search of Confucian HRM: Theory and practice in greater china and beyond. The International Journal of Human Resource Management, 21(12), 2053-2078

Whitener, E. M., Brodt, S. E., Korsgaard, M. A., \& Werner, J. M. (1998). Managers as initiators of trust: An exchange relationship framework for understanding managerial trustworthy behavior. Academy of Management Review, 23(3), 513-530

Whiteside, D. B., \& Barclay, L. J. (2016). The face of fairness: Self-awareness as a means to promote fairness among managers with low empathy. Journal of Business Ethics, 137(4), 721-730

Woods, A. (2012). Subjective adjustments to objective performance measures: The influence of prior performance. Accounting, Organizations and Society, 37(6), 403-425

Wu, P., \& Chaturvedi, S. (2009). The role of procedural justice and power distance in the relationship between high performance work systems and employee attitudes: A multilevel perspective. Journal of Management, 35(5), 1228-1247

Xu, A. J., Loi, R., \& Ngo, H. (2016). Ethical leadership behavior and employee justice perceptions: The mediating role of trust in organization. Journal of Business Ethics, 134(3), 493-504

Yang, J., Mossholder, K. W., \& Peng, T. (2009). Supervisory procedural justice effects: The mediating roles of cognitive and affective trust. The Leadership Quarterly, 20(2), 143-154

Zainuddin, S., \& Isa, C. R. (2019). The role of workplace fairness and information sharing in a budget setting process: An empirical study. Gadjah Mada International Journal of Business, 21(2), 135

Zhao, X., Lynch, J. G., Jr., \& Chen, Q. (2010). Reconsidering Baron and Kenny: Myths and truths about mediation analysis. Journal of Consumer Research, 37(2), 197-206 